\title{
IMPLEMENTASI PENGELOLAAN KEUANGAN BADAN USAHA MILIK DESA (STUDI DESA GONDOWANGI WAGIR KABUPATEN MALANG)
}

\author{
Naily Rofidah \\ UIN Maulana Malik Ibrahim Malang, \\ Jl. Gajayana No.50, Malang, 65144, Indonesia \\ e-mail : nrofidah9@gmail.com \\ Sulis Rochayatun \\ UIN Maulana Malik Ibrahim Malang, \\ Jl. Gajayana No.50, Malang, 65144, Indonesia \\ e-mail : sulis@uin-malang.ac.id
}

\section{Abstract}

Village development is the focus of national development because the village is a subsection of the national territory that directly manage the society. Nowdays villages are required to have BUMDes as a leading organization aimed to optimize village potential (Wargiyat, 2015). The management of BUMDes must be in accordance with established regulations; financial management of BUMDes is guided by Regulation of The Minister of Village (Permendes) Number 4 of 2015 and Ministry of Home Affair regulations (Permendagri) 113 of 2015. Principles that must be upheld in the management of BUMDes are cooperative, participatory, emancipatory, transparent, accountable, and sustainable.The purpose of this study is to determine the financial management of BUMDes Gondowangi in Gondowangi Village, Wagir District, Malang Regency. The type of this research is qualitative with a case study approach. The conclusions that can be taken are financial management carried out by BUMDes Gondowangi is still simple. The planning is done by holding a meeting of each unit to form the budget plan (RAB). Implementation is carried out using receipts as proof of disbursement of funds. However, the administration is done by recording cash income and expenditure. Then, Recording which is carried out is still general. Accountability is carried out by giving a report to the regional consultative committee (BPD) of Village and Community and Village Empowerment and Service (DPMD) of Malang District, as well as sending a soft file to the Ministry of Village, and delivering it to the community together with the village meeting. The accountability of regular activities in 2017 is also carried out by BUMDes Gondowangi in village meetings. Supervision in the form of guidance from the governor and regent / mayor has not been obtained by BUMDes Gondowangi.

Keywords: BUMDes, financial management

\section{Abstrak}

Pembangunan desa adalah titik berat pembangunan nasional, karena desa merupakan sub bagian wilayah nasional yang langsung menyentuh masyarakat. Pembangunan unit desa sangat berpengaruh atas pertumbuhan pembangunan nasional. Saat ini desa wajib memiliki BUMDes sebagai organisasi unggulan bertujuan guna optimalisasi potensi desa (Wargiyat, 2015). Pengelolaan BUMDes harus sesuai dengan peraturan yang telah ditetapkan, pengelolaan keuangan BUMDes berpedoman pada Permendes Nomor 4 Tahun 2015 dan Permendagri 113 Tahun 2015. Prinsip yang harus dijunjung dalam pengelolaan BUMDes yaitu kooperatif, partisipatif, emansipatif, transparan, akuntabel, dan sustainabel. 
Naily Rofidah dan Sulis Rochayatun: Implementasi Pengelolaan Keuangan Badan Usaha Milik Desa (Studi Desa Gondowangi Kecamatan Wagir Kabupaten Malang

Tujuan penelitian ini adalah untuk mengetahui pengelolaan keuangan BUMDes Gondowangi di Desa Gondowangi Kecamatan Wagir Kabupaten Malang sebagai upaya optimalisasi desa. Jenis penelitian ini yaitu kualitatif dengan pendekatan studi kasus. Narasumber dalam penelitian ini yaitu ketua BUMDes, sekretaris BUMDes, bendahara BUMDes, anggota BUMDes, pemerintah desa dan sebagian masyarakat Desa Gondowangi. Hasil penelitian menunjukan bahwa pengelolaan keuangan yang dilakukan oleh BUMDes Gondowangi masih bersifat sederhana. Perencanaan yang dilakukan yaitu dengan mengadakan rapat setiap unit untuk membentuk RAB. Pelaksanaan dilakukan dengan menggunakan kwitansi sebagai bukti pencairan dana. Penatausahaan dilakukan dengan mencatat pemasukan dan pengeluaran kas. Pencatatan yang dilakukan masih bersifat umum. Pertanggungjawaban dilakukan dengan memberikan laporan kepada BPD Desa dan DPMD Kab Malang, serta mengirim soft file kepada Kementrian Desa, dan menyampaikan kepada masyarakat bersama dengan musyawarah desa. Pertanggungjawabaan kegiatan reguler tahun 2017 juga dilakukan oleh BUMDes Gondowangi dalam musyawarah desa. Pengawasan berupa pembinaan dari gubernur dan bupati/walikotab belum diperoleh oleh BUMDes Gondowangi.

Kata kunci: BUMDes, Pengelolaan Keuangan

\section{PENDAHULUAN}

Pembangunan desa adalah titik berat pembangunan nasional, karena desa merupakan sub bagian wilayah nasional yang langsung menyentuh masyarakat. Namun hingga saat ini, masih terdapat kesenjangan antara wilayah kota dan desa. Pembangunan unit desa sangat berpengaruh atas pertumbuhan pembangunan nasional. Desa mandiri merupakan tingkat partisipasi yang tinggi dari masyarakat karena memiliki keinginan untuk maju, dibuktikan dengan hasil karya dan kemampuan desa memenuhi kebutuhannya. Desa mandiri tertumpu pada trisakti yakni; karsa, karya, dan sembada. Jika suatu desa sudah mencapai trisakti tersebut, maka desa itu dapat dikatakan desa mandiri.

Beberapa keterbatasan yang dimiliki desa dalam segi pendapatan, maka desa dituntut untuk mandiri dan menggali potensi lokal guna peningkatan dan pemberdayaan masyarakat. Pembangunan desa dengan orientasi pemanfaatan Dana Desa melalui BUMDes diharapkan dapat menggali potensi lokal desa (Prasetyo, 2016). BUM Desa, merupakan sebuah badan usaha yang bergerak di bidang komersil dan sosial yang kepemilikan dananya sebagian besar bersumber dari desa melalui penyertaan langsung yang berasal dari kekayaan desa yang dikelola secara terpisah guna pengelolaan aset, jasa pelayanan, dan usaha lainnya untuk sebesar besarnya kesejahteraan masyarakat Desa ( Undang Undang No 6 Tahun 2014). BUMDes merupakan organisasi yang bergerak di 
Naily Rofidah dan Sulis Rochayatun: Implementasi Pengelolaan Keuangan Badan Usaha Milik Desa (Studi Desa Gondowangi Kecamatan Wagir Kabupaten Malang

bidang sosial dan komersil, yaitu memberikan pelayanan sosial, disamping itu juga terdapat misi komersil bertujuan mencari laba melalui penawaran sumber daya desa ke pasar.

Pengelolaan BUMDes berpedoman pada Permendes Nomor 4 Tahun 2015 tentang pendirian, pengurusan, dan pengelolaan, dan pembubaran Badan Usaha Milik Desa. Pengelolaan Keuangan BUMDes didasari pada pengelolaan keuangan Desa yaitu Permendagri Nomor 113 Tahun 2014 yang terdiri dari perencanaan, pelaksanaan, penatausahaan, pelaporan, pertanggungjawaban. Desa wajib memiliki BUMDes sebagaimana yang disampaikan oleh Ketua Umum Dewan Pimpinan Pusat Perkumpulan Aparatur Pemerintah Desa Seluruh Indonesia (DPP PAPDESI) Wargiyat bahwa BUMDes wajib dimiiliki setiap desa sebagai organisasi unggulan bertujuan guna optimalisasi potensi desa.

Berdasarkan uraian di atas, penelitian ini memiliki rumusan masalah, yaitu : Bagaimana Pengelolaan Keuangan Badan Usaha Milik Desa (BUMDes) Gondowangi Kecamatan Wagir Kabupaten Malang dalam upaya optimalisasi desa? Penelitian ini mengacu pada penelitian yang telah dilakukan oleh Muammar Alkadafi (2015) dan Edy Yusuf (2016) menunjukan bahwa keberadaan BUMDes dapat memperkuat ekonomi desa dan penelitian yang dilakukan Dian Irawati dan Diana E Martanti (2017) bahwa pengelolaan keuangan yang dilakukan BUMDes bersifat transparan dengan menggunakan panduan "Buku Data Tanah Di Desa atau Kelurahan Asal Kabupaten". Perbedaan penelitian ini dengan penelitian sebelumnya yaitu pada penelitian ini menekankan pada pengelolaan keuangan berpedoman pada permendagri 113 tahun 2014 dan permendes nomor 4 tahun 2015 sedangkan yang sebelumnya lebih ke transparansi pada bidang Pelaporan Aset Desa. Tujuan dari penelitian ini yaitu untuk mengetahui pengelolaan keuangan BUMDes Gondowangi di Desa Gondowangi Kecamatan Wagir guna optimalisasi desa.

\section{KAJIAN PUSTAKA}

\section{Desa dan Pemerintahan Desa}

Berdasarkan Kamus Besar Bahasa Indonesia tertulis bahwa desa merupakan suatu wilayah dan ditempati oleh sekelompok keluarga yang 
Naily Rofidah dan Sulis Rochayatun: Implementasi Pengelolaan Keuangan Badan Usaha Milik Desa (Studi Desa Gondowangi Kecamatan Wagir Kabupaten Malang

memiliki sistem pemerintah mandiri (dipimpin seorang Kepala Desa). Pengertian desa menurut Peraturan Pemerintah Nomor 72 Tahun 2005 tentang Desa Pasal 1 yaitu sekumpulan masyarakat yang dilindungi oleh hukum dan mempunyai batas-batas yang bertujuan untuk mengatur kebutuhan dan kepentingan masyarakat setempat, yang disesuaikan dengan adat istiadat dan asal usul yang diakui dan dihormati dalam Sistem Pemerintah Negara Kesatuan Republik Indonesia. Desa termasuk dalam susunan sistem pemerintahan yang berada pada posisi paling bawah atau pemerintah tingkat 3 , desa adalah sub bagian dari sistem pemerintah yang dapat berinteraksi secara langsung dengan masyarakat dikarenakan posisi desa yang merupakan unit terkecil dalam pemerintah.

Desa diakui oleh pemerintah sebagaimana dalam Undang- Undang Nomor 32 Tahun 2004 tentang Pemerintah Daerah. Desa ialah suatu kesatuan masyarakat yang dilindungi hukum serta memiliki batasan wilayah kekuasaan tertentu untuk mengelolah dan mengatur rumah tangganya sendiri sesuai dengan adat istiadat yang dihormati dan diakui oleh Pemerintah Negara Kesatuan Republik Indonesia.

\section{Pengelolaan Keuangan Desa}

Keuangan desa berupa hak dan kewajiban desa yang dapat dinilai dengan uang dan dapat digunakan dalam kegiatan penyelenggaraan pemerintah desa dan kepentingan masyarakat desa (Undang- Undang No 6 Tahun 2014). Dinilai dari objek, keuangan negara ialah semua kewajiban dan hak negara yang bisa diukur dengan mata uang, termasuk kebijakan dalam bidang moneter, fiskal, maupun pengelolaan kekayaan negara. Dari segi subjek yaitu semua subjek yang menguasai objek (Undang- Undang No 17 Tahun 2003).

Keuangan negara dilihat dari sisi proses yaitu meliputi seluruh kegiatan yang berhubungan dengan pengelolaan objek, bermula dari rencana awal atau perumusan kebijakan kemudian pengambilan keputusan dan pertanggungjawaban. Sementara jika dilihat dari sisi tujuan, keuangan negara meliputi semua kegiatan, kebijakan, dan hubungan hukum yang berkaitan dengan kepemilikan atau penguasaan objek dalam rangka penyelenggaran pemerintah negara (Soleh dan Rochmansjah, 2015). 
Naily Rofidah dan Sulis Rochayatun: Implementasi Pengelolaan Keuangan Badan Usaha Milik Desa (Studi Desa Gondowangi Kecamatan Wagir Kabupaten Malang

Dalam proses pengelolaan keuangan desa sesuai dengan Undang-undang Nomor 6 Tahun 2014 tentang desa dan berpedoman pada peraturan Menteri Dalam Negeri (Permendagri) Nomor 113 Tahun 2014 tentang Keuangan Desa menyebutkan bahwa pengelolaan Keuangan Desa meliputi: Perencanaan, pelaksanaan, penataausahaan, pelaporan, pertanggungjawaban Keuangan Desa

\section{Badan Usaha Milik Desa}

BUMDes meliputi unit-unit usaha yang memiliki badan hukum. Unit usaha yang telah berbadan hukum tersebut berbentuk lembaga bisnis yang sahamnya dimiliki oleh BUMDes dan masyarakat. Struktur pengurus BUMDes antara lain : penasihat, pelaksana operasional : dan pengawas (Kamaroesid, 2016)

Tujuan pembentukan BUMDes berdasarkan Peraturan Desa Gondowangi Nomor 3 Tahun 2008 pasal 6 dan 7 yaitu meningkatkan Pendapatan Asli Desa, meningkatkan kemampaun keuangan pemerintah desa dalam penyelenggaraan program pemerintahan dan kesejahteraan masyarakat dengan beberapa program yang dijalankan, dan sebagai fungsi lembaga pelayanan.

Peraturan BUMDes yang dijadikan pedoman dalam pendirian dan pengelolaan yaitu Peraturan Kementrian Desa Pembangunan Daerah Tertinggal dan Transmigrasi Republik Indonesia No 4 Tahun 2015 dan Permendagri 113 Tahun 2014 yaitu terdiri dari perencanaan, pelaksanaan, penatausahaan, pelaporan, dan pertanggungjawaban.

Prinsip-prinsip pengelolaan BUMDes penting untuk diuraikan guna persamaan tafsir antar anggota pemerintah desa. Dalam Buku Panduan Pendirian dan Pengelolaan Badan Usaha Milik Desa (2007:13) terdapat 6 prinsip dalam pengelolaan BUMDes : partisipatif, kooperatif, emansipatif, transparan, akuntabel, dan sustainabel.

\section{METODE}

Jenis penelitian ini merupakan penelitian kualitatif deskriptif dan menggunakan pendekatan studi kasus. Jenis penelitian ini merupakan penelitian kualitatif deskriptif dan menggunakan pendekatan studi kasus. Metode kualitatif adalah prosedur penelitian yang data akhirnya berupa data deskriptif yaitu katakata tertulis maupun lisan yang bersumber dari orang-orang atau subjek yang 
Naily Rofidah dan Sulis Rochayatun: Implementasi Pengelolaan Keuangan Badan Usaha Milik Desa (Studi Desa Gondowangi Kecamatan Wagir Kabupaten Malang

diamati (Bogdan dan Taylor dalam Moleong, 2010). Pendekatan studi kasus merupakan penelitian yang mengamati status subjek penelitian yang berkaitan dengan suatu fase tertentu atau khas dari keseluruhan personalitas (Maxfield dalam Nazir 2005). Jenis penelitian ini diambil oleh penulis yaitu untuk mengetahui pengelolaan keuangan di BUMDes Gondowangi dalam upaya optimalisasi desa.

Data yang digunakan oleh peneliti yaitu data primer dan sekunder. Data primer merupakan data yang diperoleh secara langsung dari sumbernya tanpa perantara. Data primer dapat berupa pendapat atau opini yang disampaikan oleh informan tentang pengelolaan keuangan BUMDes Gondowangi dimana respondennya yaitu Ketua BUMDes, Bendahara BUMDes, Ketua setiap unit BUMDes, sebagian masyarakat Gondowangi, dan perwakilan pemerintah desa. Data sekunder penelitian ini yaitu berupa peraturan pemerintah, undangundang, buku, modul, dan jurnal yang berkaitan dengan pengelolaan keuangan BUMDes. Pada penelitian ini data sekunder berupa laporan pertanggungjawaban BUMDes tahun 2017 (Sugiyono, 2016).

Instrumen penelitian yang digunakan yaitu perekam suara, alat tulis, dan penulis menyediakan pedoman wawancara berisi pertanyaan- pertanyaan yang telah disesuaikan dengan pokok permasalahan. Selama proses wawancara peneliti mencatat hal penting yang dibutuhkan dan merekam wawancara untuk melengkapi data. Dalam penelitian ini, peneliti melakukan analisis dengan langkah sebagai berikut: Menggambarkan secara rinci, keadaan yang ada di Desa Gondowangi khususnya kondisi BUMDes Gondowangi dan pengelolaan keuangannya. Tahap ini dilakukan dari proses awal hingga proses penyelesaian. Peneliti harus mendapatkan data yang akurat sehingga mudah untuk menganalisis data- data selanjutnya. Penelitian ini membahas tentang pengelolaan keuangan yang dilakukan oleh BUMDes Gondowangi, menganalisis Pengelolaan Keuangan yang dilakukan oleh BUMDes Gondowangi dari tahap perencanaan, pelaksanaan, penatausahaan, pelaporan, dan pertanggungjawaban dan pengawasan., mengevaluasi pengelolaan keuangan BUMDes Gondowangi., proses pencatatan hasil dari penelitian lapangan dan penyajian data, penarikan kesimpulan. 
Naily Rofidah dan Sulis Rochayatun: Implementasi Pengelolaan Keuangan Badan Usaha Milik Desa (Studi Desa Gondowangi Kecamatan Wagir Kabupaten Malang

\section{HASIL DAN PEMBAHASAN}

\section{a. Perencanaan}

Perencanaan adalah kegiatan yang dilakukan oleh BUMDes Gondowangi untuk membentuk Rancangan Anggaran Biaya. Perencanaan merupakan tahap awal pengelolaan keuangan BUMDes. Tahap ini tidak selalu dilakukan oleh BUMDes Gondowangi. BUMDes Gondowangi melakukan perencanaan ketika memperoleh dana dari pemerintah atau dana dari pihak luar, jika tidak memperoleh dana mereka tidak melakukan perencanaan. Pada tahun 2017 BUMDes Gondowangi memperoleh dana dari Kementerian Desa sebesar 50 juta. BUMDes Gondowangi melakukan perencanaan dengan melakukan rapat dengan pengurus per unit nya dalam penyusunan Rancangan Anggaran Biaya.

\section{b. Pelaksanaan}

Setelah Rancangan Anggaran Biaya dibentuk dan disetujui oleh semua pengurus BUMDes Gondowangi, maka dilakukan tahap selanjutnya yaitu pelaksanaan. Pada tahap ini akan terjadi pengeluaran dan pemasukan kas. Tahap pelaksanaan berpedoman pada Rancangan Anggaran Biaya yang dibentuk pada tahap perencanaan, dana akan diberikan oleh Ketua BUMDes Gondowangi kepada setiap divisi dengan menggunakan bukti kwitansi.

Seharusnya penyerahan dana dari BUMDes ke unit pelaksana beradasarkan Permendagri No 113 Tahun 2014 Pasal 27 sampai 29 yaitu pihak pelaksana menyerahkan Surat Permintaan Pembayaran, kemudian setelah ada pencairan dana maka seharusnya ada Bukti Pencairan SPP.

\section{c. Penatausahaan}

Penatausahaan merupakan tahap ketiga dalam pengelolaan keuangan. Berdasarkan Permendagri 113 Tahun 2014, penatausahaan dilakukan oleh bendahara desa, dalam hal ini dilakukan oleh bendahara BUMDes. Semua dicantumkan dalam Laporan pertanggungjawaban BUMDes.

Penatausahaan yang dilakukan oleh BUMDes Gondowangi yaitu dilakukan oleh Ibu Yuli Ernawati, pencatatannya yang dilakukan akan dituangkan dalam laporan pertanggungjawaban. Laporan pertanggungjawaban BUMDes Gondowangi dilakukan terpisah dengan 
Naily Rofidah dan Sulis Rochayatun: Implementasi Pengelolaan Keuangan Badan Usaha Milik Desa (Studi Desa Gondowangi Kecamatan Wagir Kabupaten Malang

program reguler. Kas umum hanya ditulis secara sederhana hanya pemasukan dan pengeluaran kas dari BUMDes kepada pelaksana. Seharusnya pencatatan yang dilakukan lebih detail. BUMDes Gondowangi seharusnya mencatat pengeluaran yang dilakukan, kemudian memposting ke dalam buku besar. Setelah itu membuat Laporan Keuangan.

\section{d. Pertanggungjawaban}

Pertanggungjawaban merupakan bentuk tanggung jawab atas penggunaan dana publik yang telah dipercayakan kepada pengurus BUMDes Gondowangi. Pertanggungjawaban yang dilakukan oleh BUMDes Gondowangi yaitu dengan memberikan laporan pertanggungjawaban kepada BPD dan Dinas Pemberdayaan Masyarakat dan Desa Kabupaten Malang dengan membawa foto copy bukti kwitansi pembelian dan berkasberkas yang dibutuhkan, selain memberikan laporan keuangan fisik BUMDes Gondowangi juga melakukan pertanggungjawaban dengan mengirim file kepada Kementrian Desa. Laporan pertanggungjawaban BUMDes Gondowangi Tahun 2017 dalam kegiatan reguler dilakukan akhir tahun bersama dengan musyawarah desa.

\section{e. Pengawasan}

Pengawasan dilakukan dalam pelaksanaaan kegiatan BUMDes agar jalannya kegiatan sesuai dengan tujuan awal yang ditetapkan bersama. Menurut peraturan Kementrian Desa seharusnya pembinaan dan pengawasan dilakukan oleh gubernur dan walikota. Gubernur melakukan sosialisasi atau penyuluhan mengenai pengelolaan BUMDes dan bupati/ walikota melakukan pembinaan, pemantauan dan evaluasi terhadap pengembangan manajemen dan sumber daya manusia. Namun BUMDes Gondowangi belum mendapatkan pembinaan secara langsung baik dari gubernur atau bupati/walikota.

Pengawasan yang dilakukan BUMDes Gondowangi kepada tim pelaksana yaitu turun lapangan ketika kegiatan berlangsung. Namun tidak ada dokumen resmi dalam pengawasan. 
Naily Rofidah dan Sulis Rochayatun: Implementasi Pengelolaan Keuangan Badan Usaha Milik Desa (Studi Desa Gondowangi Kecamatan Wagir Kabupaten Malang

\section{KESIMPULAN DAN SARAN}

Dari penelitian yang dilakukan dapat disimpulkan bahwa :

1. Tahap perencanaan yang dilakukan oleh BUMDes Gondowangi pada program yang diberikan oleh Kementrian Desa senilai 50 juta tahun 2017 yaitu dengan mengadakan rapat setiap unit untuk membentuk Rancangan Anggaran Biaya.

2. Tahap pelaksanaan dilakukan oleh bendahara BUMDes dengan menggunakan kwitansi sebagai bukti pencairan dana.

3. Penatausahaan dilakukan oleh bendahara desa dengan mencatat pemasukan dan pengeluaran kas.

4. Pertanggungjawaban yang dilakukan oleh BUMDes Gondowangi berkaitan dengan dana 50 juta yang diberikan oleh Kementrian Desa yaitu dengan memberikan laporan kepada BPD Desa dan DPMD Kab Malang, serta mengirim soft file kepada Kementrian Desa. Program pada tahun 2017 disampaiakn oleh pengurus BUMDes kepada masyarakat dalam musyawarah desa yang dilakukan akhir tahun.

5. Pengawasan yang dilakukan oleh gubernur dan bupati/walikota berupa pembinaan belum didapat oleh BUMDes Gondowangi sedangkapan pengawasan yang dilakukan BUMDes Gondowangi kepada pelaksana dalam kegiatan BUMDes yaitu dengan turun lapangan meskipun tidak ada dokumen resmi.

Pertanggungjawabaan kegiatan reguler tahun 2017 juga dilakukan oleh BUMDes Gondowangi dalam musyawarah desa. Berdasarkan penelitian yang dilakukan, penulis menyarankan :

1. Tahap pelaksanaan yang dilakukan oleh BUMDes Gondowangi seharusnya menggunakan SPP dan Bukti Pencairan SPP sesuai dengan Permendagri No 113 Tahun 2014 .

2. Tahap penatausahaan yang dilakukan BUMDes Gondowangi masih bersifat umum, seharusnya pencatatan yang dilakukann oleh BUMDes Gondowangi harus detail kemudian melakukan posting ke buku besar untuk menghasilkan Laporan Keuangan 
Naily Rofidah dan Sulis Rochayatun: Implementasi Pengelolaan Keuangan Badan Usaha Milik Desa (Studi Desa Gondowangi Kecamatan Wagir Kabupaten Malang

3. Tahap pertanggungjawaban yang dilakukan oleh BUMDes Gondowangi harusnya setiap satu tahun dilakukan sekurang- kurangnya 2 kali, namun masih dilaksanakan satu kali yaitu pada akhir tahun.

\section{DAFTAR PUSTAKA}

Agunggunanto, Edy Yusuf dkk. 2016. Pengembangan Desa Mandiri melalui Pengelolaan Badan Usaha Milik Desa (BUMDes)

Departemen Pendidikan Nasional Pusat Kajian Dinamika Sistem Pembangunan (PKDSP). 2007. Buku Panduan Pendirian dan Pengelolaan Badan Usaha Milik Desa (BUMDes).

Dina Irawati, Diana Elvianita Martanti (2017). Transparansi Pengelolaan Laporan Keuangan BUMDes Terhadap Pelaporan Aset Desa (Studi Fenomenologi Pada BUMDes Desa Karangbendo Kec Ponggok Kab Blitar). SNAPER-EBIS. Jember. Hal 41-51

Kamaroseid, Herry. 2016. Tata Cara Pendirian dan Pengelolaan Badan Usaha Milik Desa. Jakarta : Mitra Wacana Media.

KBBI, 2016. Kamus Besar Bahasa Indonesia (KBBI). [Online] Available at: http://kbbi.web.id/pusat (diakses tanggal 3 Januari 2019)

Moleong, L. J. 2010. Metodologi Penelitian Kualitatif, Bandung : Remaja Rosda.

Muammar Alkadafi, S.Sos, M.Si. 2015. Penguatan Ekonomi Masyarakat Melalui Pengelolaan Kelembagaan Badan Usaha Milik Desa Menuju Asean Economic Community. Jurnal El Riyasah. Riau.

Nazir, Moh. 2005. Metodologi Penelitian. Bogor Selatan : Ghalia Indonesia Peraturan Desa Gondowangi Nomor 3 Tahun 2008.

Peraturan Menteri Dalam Negeri Republik Indonesia Nomor 113 Tahun 2014 Tentang Pengelolaan Keuangan Desa

Peraturan Menteri Desa, Pembangunan Daerah Tertinggal, dan Transparansi Republik Indonesai No 4 Tahun 2015 Tentang Pendirian, Pengurusan DAN Pengelolaan, dan Pembubaran Badan Usaha Milik Desa.

Peraturan Pemerintah Nomor 72 Tahun 2005 Tentang Desa

Ratna Azis Prasetyo. 2016. Peranan BUMDes Dalam Pembangunan Dan Pemberdayaan Masyarakat Di Desa Pejambon Kecamatan Sumberrejo Kabupaten Bojonegoro. Jurnal Dialektika. Surabaya. 
Naily Rofidah dan Sulis Rochayatun: Implementasi Pengelolaan Keuangan Badan Usaha Milik Desa (Studi Desa Gondowangi Kecamatan Wagir Kabupaten Malang

Soleh, Chabib dan Heru Rochmanjah. 201. Pengelolaan Keuangan Desa. Bandung : Fokus Media

Sugiyono. 2016. Metode Penelitian Kuantitatif, Kualitatif dan R\&D. Bandung: PT Alfabet.

Undang- Undang No 6 Tahun 2014 Tentang Desa.

Undang- Undang No 17 Tahun 2003 Tentang Keuangan Negara.

Undang- Undang Nomor 32 Tahun 2004 tentang Pemerintah Daerah. 